\title{
EU NÃO SOU DA SUA RUA: O REGISTRO EM TEXTO E FOTOGRAFIA DE MORADORES DE RUA EM PRESIDENTE PRUDENTE
}

Maria Luisa Hoffmann, Roberto Aparecido Mancuzo Silva Junior

Universidade do Oeste Paulista, Curso de Comunicação Social, Presidente Prudente, SP. E-mail: marialuisa@unoeste.br; mancuzo@unoeste.br

\section{RESUMO}

A presente pesquisa teve como objetivo documentar a vida de moradores de rua da cidade de Presidente Prudente através de um fotolivro com textos de perfil. Para tanto, foi necessário compreender o contexto de vida desses indivíduos através da pesquisa qualitativa e exploratória. Como método utilizou-se o estudo de caso, com o suporte de técnicas como a pesquisa bibliográfica, observação intensiva e entrevistas. O estudo permitiu novas reflexões e discussões acerca da situação em que vivem os moradores de rua da cidade assim como sobre o papel do jornalista na atualidade. O fotolivro produzido contém 49 fotografias de 12 personagens selecionados.

Palavras-chave: fotografia documental; fotolivro; texto de perfil; moradores de rua; Presidente Prudente.

\section{AM NOT FROM YOUR STREET: THE TEXT AND PHOTOGRAPH REGISTRY OF HOMELESS IN PRUDENT PRESIDENT}

\begin{abstract}
The present research documented the live of homeless people in the city of Presidente Prudente through a photobook with profile texts. Therefore, it was necessary to understand the life context of these individuals through qualitative and exploratory research. Study of case was used as method, with the support of techniques such as bibliographic research, intensive observation and interviews. The study allowed new reflections and discussions about the situation of homeless people in the city and about the journalist's role nowadays. The photobook produced contains 49 photographs of 12 selected characters.
\end{abstract}

Keywords: documentary photography; photobook; profile text; homeless; Presidente Prudente. 


\section{INTRODUÇÃO}

A assistência Social no Brasil é um direito reservado a todo indivíduo que necessita da ajuda do Estado para obter melhores condições dentro da sociedade. O cidadão carente, de qualquer idade, deve ter a proteção e o amparo através do agrupamento de ações entre iniciativas públicas, privadas e de sociedade civil.

O Estado, por sua vez, oferece muitas vezes atendimento em prol da vida de pessoas que estão em situação de rua. Na cidade de Presidente Prudente, tem-se o registro de 153 moradores que desfrutam das ações como acolhimento durante a noite e alimentação ao longo do dia.

A presente pesquisa buscou evidenciar a situação em que vivem alguns moradores de rua em Presidente Prudente, procurando entender a realidade vivenciada por eles, bem como os motivos de permanência nas ruas. Para tanto, foram observados vários moradores e selecionados 12 personagens para a construção de um fotolivro com textos de perfil. Para tais fins, foram utilizados métodos científicos de coleta e análise de dados.

O desenvolvimento do trabalho foi baseado na seguinte questão: como fazer com que o jornalismo torne visível a situação dos moradores de rua da cidade de Presidente Prudente? A escolha do tema se deu pelo desejo de relatar histórias inspiradas no jornalismo humanizado e de exercitar a prática da fotodocumentação e da intencionalidade fotográfica. O objetivo geral da pesquisa foi o de produzir um fotolivro composto por 12 histórias de moradores de rua da cidade Presidente Prudente.

\section{METODOLOGIA}

A metodologia foi necessária para a definição e realização dos procedimentos, na busca de alcançar o objetivo definido na pesquisa científica. Sendo assim, o método se torna um guia para a elaboração do trabalho e para a compreensão de seus resultados. Lakatos e Marconi (2005, p.82) definem o método como:

[...] conjunto das atividades sistemáticas e racionais que, com maior segurança e economia, permite alcançar o objetivo - conhecimentos válidos e verdadeiros -, traçando o caminho a ser seguido, detectando erros e auxiliando as decisões do cientista.

Para a realização desse trabalho, foi adotada a pesquisa qualitativa, pois busca compreender o objeto de estudo com detalhes e descrições de situações que não são passíveis de serem quantificadas ou traduzidas em números e estatísticas. Goldenberg (2004, p.53) explica:

Os dados qualitativos consistem em descrições detalhadas de situações com o objetivo de compreender os indivíduos em seus próprios termos. Estes dados não são padronizáveis como os dados quantitativos, obrigando o pesquisador a ter flexibilidade e criatividade no momento de coletá-los e analisa-los. Não existindo regras precisas e passos a serem seguidos, o bom resultado da pesquisa depende da sensibilidade, intuição e experiência do pesquisador.

Por possibilitar uma maior flexibilidade sobre o assunto, tornando considerações mais variáveis, a abordagem escolhida foi a exploratória. Segundo Gil (2002, p.41):

As pesquisas exploratórias têm como principal finalidade desenvolver, esclarecer e modificar conceitos e ideias, tendo em vista a formulação de problemas mais precisos ou hipóteses pesquisáveis para estudos posteriores. De todos os tipos de pesquisa, estas são as que apresentam menor rigidez no planejamento. 
Habitualmente envolvem levantamento bibliográfico e documental, entrevistas não padronizadas e estudos de caso.

Já o método utilizado foi o estudo de caso, tendo em vista que permite um conhecimento amplo sobre unidades-caso. "[...] consiste no estudo profundo e exaustivo de um ou poucos objetos, de maneira que permita seu amplo e detalhado conhecimento, tarefa praticamente impossível mediante outros delineamentos já considerados." (GIL, 2012, p.58)

Yin (2010, p.39) define o estudo de caso como "uma investigação empírica que investiga um fenômeno contemporâneo em profundidade e em seu contexto de vida real, especialmente quando os limites entre o fenômeno e o contexto não são claramente evidentes".

Ademais, para alcançar o objetivo proposto foi necessário usar técnicas para levantamento de dados, dentre elas a pesquisa bibliográfica, utilizada para coletar informações presentes em livros e sites especializados, bem como artigos científicos. Stumpf (2014, p.51) define:

Pesquisa bibliográfica, num sentido amplo, é o planejamento global inicial de qualquer trabalho de pesquisa que vai desde a identificação, localização e obtenção da bibliografia pertinente sobre o assunto, até a apresentação de um texto sistematizado, onde é apresentada toda a literatura que o aluno examinou, de forma a evidenciar o entendimento do pensamento dos autores, acrescido de suas próprias ideias e opiniões.

Outra técnica utilizada para entender o contexto em que vivem os moradores em situação de rua foi a pesquisa de campo, com observação direta intensiva e entrevista em profundidade. Gil (2002, p. 53) define a pesquisa de campo como aquela que estuda "[...] um único grupo ou comunidade em termos de sua estrutura social, ou seja, ressaltando a interação entre seus componentes. Dessa forma, o estudo de campo tende a utilizar muito mais técnicas de observação do que de interrogação." Sendo assim, os integrantes do grupo estiveram presentes no Centro Especializado para População em Situação de Rua (CREAS), Centro de referência de Assistência Social (CRAS) e Secretária de Assistência Social (SAS), a fim de entrevistar profissionais que atuam nesses órgãos bem como os assistidos. Duarte $(2009$, p.62) define que

A entrevista em profundidade é um recurso metodológico que busca, com base em teorias e pressupostos definidos pelo investigador, recolher respostas a partir da experiência subjetiva de uma fonte, selecionada por deter informações que se deseja conhecer.

O objetivo do procedimento era o de obter informações sobre a vida dos indivíduos para a construção do fotolivro e para a compreensão de sua realidade. Lakatos e Marconi (2005, p.195) definem a técnica como "um procedimento utilizado na investigação social, para a coleta de dados ou para ajudar no diagnóstico ou no tratamento de um problema social". Enquanto gênero jornalístico, a entrevista possibilitou a construção dos textos de perfil.

Já a observação direta intensiva foi realizada nos centros de acolhimento assim como nas ruas e praças da cidade, onde vivem os personagens selecionados. A técnica possibilita "conseguir informações e utiliza os sentidos na obtenção de determinados aspectos da 
realidade. Não consiste apenas em ver e ouvir, mas também em examinar fatos ou fenômenos que se desejam estudar." (LAKATOS; MARCONI, 2005, p.190)

Nesse momento, foram produzidas centenas de imagens para posterior reflexão sobre condições de vida e rotinas dos moradores. As imagens que documentaram o perfil dos moradores de rua foram elaboradas em P\&B. Sendo assim, os pesquisadores observaram os indivíduos e fotografaram suas ações, buscando mostrá-los em situação de rua e durante o acolhimento.

Para analisar os resultados, utilizou-se a técnica de triangulação de dados, com cruzamento das informações coletadas. Trata-se de "uma ferramenta útil ao pesquisador sobretudo qualitativo - que deseja aumentar a confiabilidade dos resultados de sua pesquisa e de suas conclusões." (ZAPPELLINI; FEUERSCHÜTTE, 2015, p. 268)

Por tratar de seres humanos, a pesquisa foi submetida à avaliação por um comitê ético e cadastrada na Plataforma Brasil, para apreciação (n. CAAE: 63674117.4.0000.5515), sendo aprovada.

\section{RESULTADOS}

A rotina dos moradores é marcada pela individualidade e solidão e, apesar das necessidades pelas quais passam, a maioria dos moradores pode contar com locais de recolhimento, seja casa de familiares ou abrigos cedidos pelo poder público.

Nas visitas e entrevistas realizadas pelos pesquisadores, percebeu-se que grande parte dos indivíduos observados é usuária de drogas ou de álcool. Segundo a avaliação dos assistentes sociais, essa prática é resultado de uma série de fatores recorrentes da vida desses sujeitos, que encontram no prazer momentâneo uma válvula de escape.

O conflito familiar é uma das causas mais frequentes do isolamento social dos indivíduos pesquisados. Outros motivos são o uso de álcool/drogas ou até questões relacionadas à sexualidade, como a homossexualidade. Existem também os que acabam na rua pela falta de oportunidades, apesar dessa ser a menor parcela do grupo observado. Segundo o IBGE (DESEMPREGO..., 2018), o desemprego no Brasil em 2017 atingiu 12,7\% da população, sendo essa uma das causas da falta de moradia. Existem também aqueles que estão saindo ou saíram das ruas, e que contam com a ajuda de programas sociais.

\section{DISCUSSÃO}

Foi possível levantar, através da metodologia e das técnicas descritas, os possíveis fatores que levam indivíduos à situação de rua em Presidente Prudente, sendo eles brigas familiares, uso de drogas/álcool, questões envolvendo sexualidade e falta de oportunidades.

Dentre as contribuições do Estado para a melhoria na situação de vida dessas pessoas, está o Sistema Único da Assistência (SUAS). Segundo a Secretaria Municipal de Desenvolvimento Social de Presidente Prudente, essa ação é dividida em duas vertentes, denominadas como Proteção Social Básica e Proteção Social Especial. A primeira é destinada a indivíduos que se encontram em situações causadas pela pobreza e falta de inclusão na sociedade, sendo que a atuação acontece nos Centros de Referência de Assistência Social (CRAS), local que presta serviços socioassistenciais direcionados para crianças, jovens e idosos. A segunda destina-se a situações de riscos decorrentes do abuso sexual, violência física ou psicológica e abandono. Essa proteção atende famílias e indivíduos no Centro de Referência Especializado da Assistência Social (CREAS), que desenvolve um 
acompanhamento especializado com o objetivo de fortalecer a rede de assistências sociais, sendo um deles o Serviço de Acolhimento para pessoas em Situação de Rua.

O órgão é mantido pela Secretaria Municipal de Assistência Social e disponibiliza atendimentos especializados para pessoas que buscam abrigo temporário. Há ainda o Centro Especializado para População em Situação de Rua, responsável pela primeira abordagem e que oferece atividades diárias para os indivíduos, além de atendimentos médicos aos moradores que se encontram fora do local. No entanto, apesar de terem garantidos por lei abrigo, alimentação, saúde e condição de recuperação do estado em que se encontram, essa população vive ainda em estado de exclusão diante da sociedade. Sentem-se marginalizados e, apesar de conviverem diariamente nas ruas da cidade, quase não são vistos, sendo esse um fator que gera grande incômodo.

Com a pesquisa foi também possível repensar a atuação do jornalista em tempos atuais. $\mathrm{O}$ grande desafio é adaptar diferentes habilidades como produção de imagens, textos e diagramação. Ou seja, o jornalista deve ser, na atualidade, polivalente.

Sobre o fotolivro, é possível observar que alguns personagens estão bem trajados em alguns momentos. Isso não significa que o grupo não buscou por personagens em situação drástica de higiene e vestuário, também não significa que os pesquisadores queriam explorar a miséria humana. O que de fato acontece é que os serviços de acolhimento da cidade fazem bem seu papel no auxílio aos moradores de rua e muitas vezes, os moradores preferem ser fotografados após um banho e uma refeição. O fotolivro produzido conta com 26 lâminas e 49 fotografias (FIGURA 1).

Figura 1. Capa

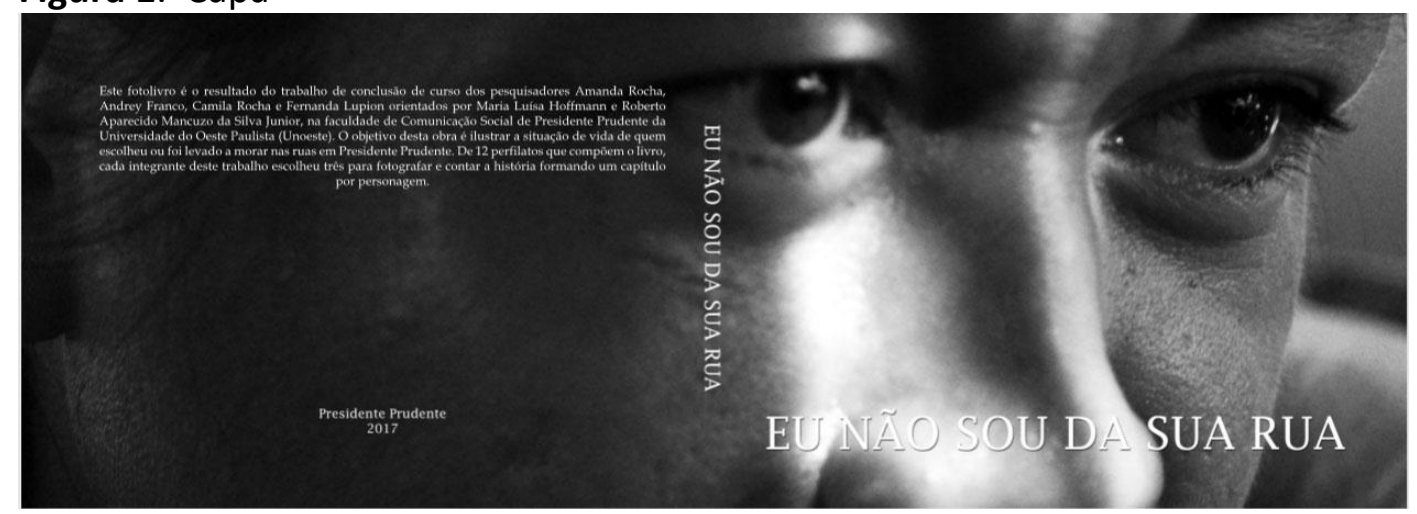

Fonte: Fotolivro produzido no projeto.

\section{CONCLUSÕES}

A documentação fotográfica atrelada ao texto jornalístico foi importante para abrir novas discussões e reflexões sobre as necessidades de um grupo que passa, muitas vezes, despercebido na sociedade. Foi possível observar que esses indivíduos recebem assistência de programas sociais na cidade e que alguns buscam sair da situação de rua com o apoio de programas.

Ademais, o trabalho ampliou as fontes de pesquisas com a produção do fotolivro, visto que a junção da fotografia documental e o texto jornalístico tornou o assunto mais próximo da realidade relatada. Segundo Fernandez (2011), o fotolivro não é apenas um mero livro ilustrativo criado por alguém. Trata-se do esforço e dedicação de um autor que pretende expor uma narrativa iconográfica por meio de um conjunto de fotografias para 
criar um discurso visual, tendo como suporte também o texto escrito. Portanto, essa obra é um produto cultural de expressão, que tende a ser híbrido em nome da comunicação.

Também foi possível observar que esse tipo de trabalho requer muito tempo de produção. $O$ vínculo de confiança que se deve criar com o observado deve ser grande, pois nem sempre estão dispostos a serem fotografados na situação em que se encontram. Portanto, esse é um trabalho que requer paciência, confiança por parte dos dois lados e investimento para um equipamento fotográfico de qualidade.

Constatou-se que a temática não é muito explorada da forma como foi feita nessa pesquisa, com a união de texto e imagens. Chega-se à conclusão de que essa é uma maneira original de contar uma história de forma jornalística, mostrando o lado humano daqueles que passam despercebidos pelas ruas. 


\section{REFERÊNCIAS}

DESEMPREGO volta a crescer com 13,1 milhões de pessoas em busca de ocupação. Disponível em: https://agenciadenoticias.ibge.gov.br/agencia-noticias/2012-agencia-denoticias/noticias/20674-desemprego-volta-a-crescer-com-13-1-milhoes-de-pessoas-embusca-de-ocupacao.html. Acesso em: 20 abr. 2018.

DUARTE, Jorge. Entrevista em profundidade. In: DUARTE, Barros; BARROS, Antonio; NOVELI, Ana. (Orgs.). Métodos e técnicas de pesquisa em Comunicação. 2. ed. São Paulo: Atlas, 2009.

FERNÁNDEZ, Horacio. Fotolivros latino-americanos. São Paulo: Cosac Naify, 2011.

GIL, Antonio Carlos. Como elaborar projetos de pesquisa. 4. ed. São Paulo: Atlas, 2002.

GIL, Antonio Carlos. Métodos e técnicas de pesquisa social. 6. ed. São Paulo: Atlas, 2012.

GOLDENBERG, Mirian. A arte de pesquisar: como fazer pesquisa qualitativa em ciências sociais. 8. ed. Rio de Janeiro: Record, 2004.

LAKATOS, Eva Maria; MARCONI, Marina de Andrade. Fundamentos de metodologia científica. São Paulo: Atlas, 2005.

STUMPF, Ida Regina. Pesquisa bibliográfica. In: DUARTE, Jorge; BARROS, A. Métodos e técnicas de pesquisa em Comunicação. 2.ed. São Paulo: Atlas 2009.

YIN, Robert K. Estudo de caso planejamento e métodos. Bookman, 2010.

ZAPPELLINI, Marcelo Beckert; FEUERSCHÜTTE, Simone Ghisi. O uso da triangulação na pesquisa científica brasileira em administração. Rio de Janeiro: 2015 Disponível em: file://C:/Users/Acer/Downloads/238-358-2-PB.pdf Acesso em: 14 Jan. 2017. 